Molecules 2003, 8, 882-885

\title{
molecules
}

ISSN 1420-3049

http://www.mdpi.org

\section{A Carboxylic Acid from Ilex integra}

Motoo Tori,* Yoshie Mukai, Katsuyuki Nakashima, and Masakazu Sono

Faculty of Pharmaceutical Sciences, Tokushima Bunri University, Yamashiro-cho, Tokushima, 770-8514, Japan. Tel + 81 (88)-622-9611, Fax: +81 (88) 655-3051; homepage :

http://p.bunri-u.ac.jp/ tori/english/e-tori.html

* Author to whom correspondence should be addressed. e-mail tori@ph.bunri-u.ac.jp

Received: 18 October 2003; in revised form: 18 December 2003 / Accepted: 18 December 2003 /

Published: 31 December 2003

\begin{abstract}
E,14E,17E)-11-Hydroxy-12,14,17-dodecatrienoic acid was isolated from the stems of Ilex integra and its structure was determined on the basis of the spectroscopic data of its methyl ester.
\end{abstract}

Keywords: Ilex integra, carboxylic acid, triene, hydroxyl group.

\section{Introduction}

In the continuous search for physiologically active compounds in plants, we had a chance to investigate the chemical constituents of Ilex integra. This plant has already been studied by several workers [1-3] and triterpenes as well as its saponins have been reported so far [1,2]. Since it has been used as birdlime in Japan, leaves [1], fruits [2], and seeds [3] were investigated. Antimicrobial activities were reported for some triterpenes [2]. Although the fatty acid mixture was investigated using GC-MS [3], no structures were suggested. We have now found 
11-hydroxy-12,14,17-dodecatrienoic acid in the leaves and stems of I. integra. The absolute configuration, however, was not determined. Here, we report the details of the new compound.

\section{Results and Discussion}

The methanol extract of I. integra was partitioned between EtOAc and water. The EtOAc soluble parts were subjected to silica gel column chromatography using gradients of hexane-EtOAc and $\mathrm{CHCl}_{3}-\mathrm{MeOH}$, as eluents. The main fraction was further purified by HPLC (hexane-EtOAc) to give a polar fraction, which was treated with $\mathrm{CH}_{2} \mathrm{~N}_{2}$. The residue was further purified by column chromatography to afford a methyl ester $\mathbf{1}$.

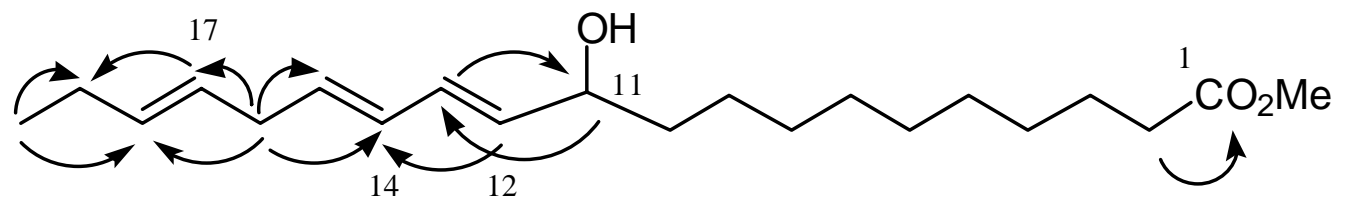

Figure 1. Selected HMBC correlations of compound $\mathbf{1}$.

The ester 1 exhibited a quasi-molecular ion peak at $\mathrm{m} / \mathrm{z} 337$ and its molecular formula was determined as $\mathrm{C}_{21} \mathrm{H}_{36} \mathrm{O}_{3}$ by CIHRMS. The IR spectrum showed the absorptions at $3450(\mathrm{OH}), 1740$ $(\mathrm{CO})$, and $1650(\mathrm{C}=\mathrm{C}) \mathrm{cm}^{-1}$. The ${ }^{13} \mathrm{C}-\mathrm{NMR}$ spectrum indicated the presence of three double bonds and a carbonyl group. The ${ }^{1} \mathrm{H}-\mathrm{NMR}$ spectrum exhibited the methine proton at $4.16 \mathrm{ppm}$ (Table 1). The COSY spectrum showed the connectivity from the $\mathrm{C} 20$ methyl group to the $\mathrm{C} 11$ methine proton, the sequence of which was supported by the fragmentation of the mass spectrum (Figure 2). The HMBC spectrum also indicated the connectivity shown by the arrows, drawn in the structure shown in Figure 1. The protons and carbons at $\mathrm{C} 3-\mathrm{C} 10$ were not assigned. The geometries of double bonds were assigned by the coupling constants. Namely, the $J$ value for C12-C13 was $15 \mathrm{~Hz}, \mathrm{C} 14-\mathrm{C} 15$ was $15 \mathrm{~Hz}$, and $\mathrm{C} 17-\mathrm{C} 18$ was $15 \mathrm{~Hz}$, suggesting all E-configuration. Consequently, the structure of the original natural product was established as (12E,14E,17E)-11-hydroxy-12,14,17-dodecatrienoic acid. The absolute configuration was not determined due to the minute quantity of the compound.

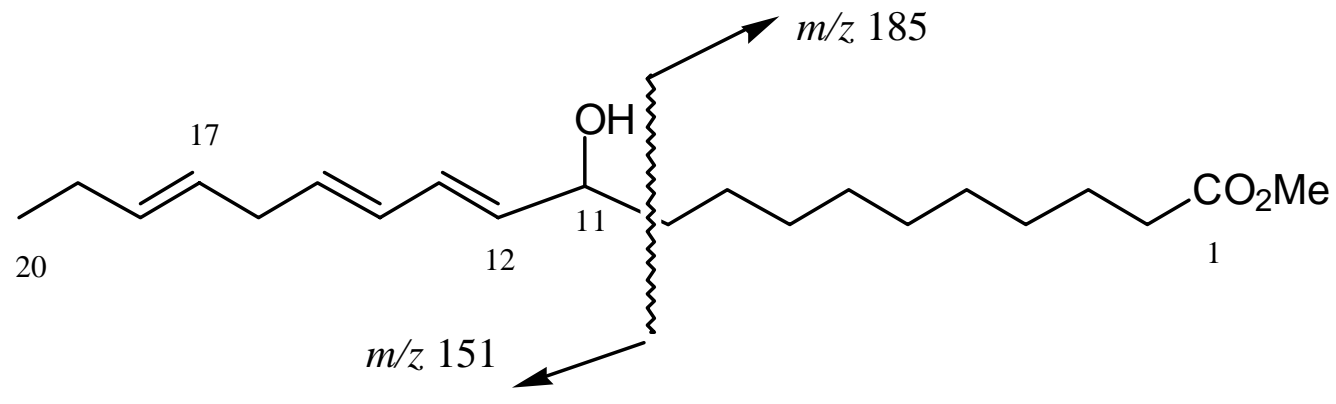

Figure 2. MS fragmentation pattern of compound 1. 


\section{Acknowledgements}

We thank Dr. Masami Tanaka and Ms. Yasuko Okamoto (our university) for measurement of the NMR and MS spectra, respectively.

\section{Experimental}

\section{General}

The IR spectra were measured with a JASCO FT/IR-500 spectrophotometer. The ${ }^{1} \mathrm{H}-$ and ${ }^{13} \mathrm{C}$-NMR spectra were recorded on a Varian Unity 600 spectrometer. Deuteriochloroform was used as solvent and chemical shifts are expressed in ppm and the coupling constants in Hz. The mass spectra, including high-resolution mass spectra, were taken with a JEOL AX-500 spectrometer. The specific rotation was measured with a JASCO DIP-100 polarimeter. Silica gel BW-300 (200-400 mesh, Fuji silycia) was used for column chromatography, and silica gel $60 \mathrm{~F}_{254}$ plates $(0.25 \mathrm{~mm}$, Merck) were used for TLC. Chemcopak Nucleosil 50-5 $(10 \times 250 \mathrm{~mm})$ was used for HPLC (JASCO pump system).

\section{Plant material}

The leaves and stems of I. integra $(11 \mathrm{~kg})$ were collected in Tokushima, in May, 1998. The tree was identified by Mr. Toshiyuki Miyamoto (Miyamoto Zo-en Co. and Lit., Tokushima Japan).

\section{Extraction and isolation}

Half dried I. integra leaves and stems $(11 \mathrm{~kg})$ were chopped into pieces and this plant mass was extracted with $\mathrm{MeOH}$. The $\mathrm{MeOH}$ extract $(1.16 \mathrm{~kg}$ ) was partitioned between EtOAc (353 g) and water. A part of the EtOAc soluble fractions $(63.3 \mathrm{~g})$ was repeatedly separated by column chromatography (elution with gradients of hexane-EtOAc and $\mathrm{CHCl}_{3}-\mathrm{MeOH}$ ), in combination with HPLC, and the resulting polar fraction was methylated with diazomethane. The esterified residue was again purified by column chromatography (elution with hexane-EtOAc, in gradients) to give compound $\mathbf{1}$ (1.6 mg); $[\alpha]_{\mathrm{D}}{ }^{19.5}-6.9\left(\mathrm{c} 0.16, \mathrm{CHCl}_{3}\right)$; MS (CI) $\mathrm{m} / z, 337[\mathrm{M}+\mathrm{H}]^{+}$319, 291 (base), 277, 259, 225, 185, and 155; HRMS (CI) Obs. $337.2756[\mathrm{M}+\mathrm{H}]^{+}$Calcd for $\mathrm{C}_{21} \mathrm{H}_{37} \mathrm{O}_{3}$ 337.2742; FT-IR (KBr) 3450, 1740, and 1650 $\mathrm{cm}^{-1} ;{ }^{13} \mathrm{C}-\mathrm{NMR}(600 \mathrm{MHz}) \delta 174.3$ (C-1), 136.3 (C-12), 132.4 (C-15), 130.7 (C-18), 127.8 (C-14), $126.5(\mathrm{C}-17), 125.5(\mathrm{C}-13), 72.8(\mathrm{C}-11), 51.5\left(\mathrm{OCH}_{3}\right), 37.3\left(\mathrm{CH}_{2}\right), 34.1(\mathrm{C}-2), 29.3\left(\mathrm{CH}_{2}\right), 29.2\left(\mathrm{CH}_{2}\right)$, $29.1\left(\mathrm{CH}_{2}\right), 29.0\left(\mathrm{CH}_{2}\right), 26.0(\mathrm{C}-16), 25.3\left(\mathrm{CH}_{2}\right), 24.9\left(\mathrm{CH}_{2}\right), 22.5\left(\mathrm{CH}_{2}\right), 20.6(\mathrm{C}-19), 14.2(\mathrm{C}-20)$; 
${ }^{1} \mathrm{H}-\mathrm{NMR} \delta 6.52(1 \mathrm{H}, \mathrm{ddt}, \mathrm{J}=15.2,11.0,1.1 \mathrm{~Hz}, \mathrm{H}-13), 5.99(1 \mathrm{H}, \mathrm{t}, \mathrm{J}=11.0 \mathrm{~Hz}, \mathrm{H}-14), 5.68(1 \mathrm{H}, \mathrm{dd}$, $\mathrm{J}=15.2,6.9 \mathrm{~Hz}, \mathrm{H}-12), 5.43(1 \mathrm{H}, \mathrm{m}, \mathrm{H}-15), 5.41(1 \mathrm{H}, \mathrm{m}, \mathrm{H}-18), 5.32(1 \mathrm{H}, \mathrm{m}, \mathrm{H}-17), 4.16(1 \mathrm{H}, \mathrm{dt}$, $\mathrm{J}=6.9,6.3 \mathrm{~Hz}, \mathrm{H}-11), 3.67$ (3H, s, OMe), $2.93(2 \mathrm{H}, \mathrm{t}, \mathrm{J}=7.4 \mathrm{~Hz}, \mathrm{H}-16), 2.30$ (2H, t, J=7.5 Hz, H-2), 2.08 (2H, qdd, J=7.7, 7.7, 0.8, H-19), 1.25-1.62 (17H, m), 0.98 (3H, t, J=7.7 Hz, H-20).

\section{References}

1. Yano, I.; Nishiizumi, C.; Yoshikawa, K.; Arihara, S. Triterpenoids saponins from Ilex integra. Phytochemistry 1993, 32, 417-420.

2. Haraguchi, H.; Kataoka, S.; Okamoto, S.; Hanafi, M.; Shibata, K. Antimicrobial triterpenes from Ilex integra and the mechanism of antifungal action. Phytotherapy Res. 1999, 13, 151-156.

3. Hirose, M.; Kosuzume, K.; Goshima, M.; Tanabe, F.; Satoh, Y.; Hagitani, A. The constituents of the seeds of Ilex integra Thunb. Part I. The components of the fatty acids of seeds of Ilex integra Thunb (Mochinoki). Yukagaku 1971, 20, 7-9.

Sample Availability: Samples not available.

(C) 2003 by MDPI (http://www.mdpi.org). Reproduction is permitted for noncommercial purposes. 